\title{
A Study on the Effect of Web Live Broadcast on Consumers' Willingness to Purchase
}

\author{
Jinhua Tong \\ School of Business Administration, South China University of Technology, Guangzhou, China \\ Email: fjctdltsh9025@126.com
}

How to cite this paper: Tong, J.H. (2017) A Study on the Effect of Web Live Broadcast on Consumers' Willingness to Purchase. Open Journal of Business and Management, 5, 280-289. https://doi.org/10.4236/ojbm.2017.52025

Received: March 20, 2017

Accepted: April 11, 2017

Published: April 14, 2017

Copyright $\odot 2017$ by author and Scientific Research Publishing Inc. This work is licensed under the Creative Commons Attribution International License (CC BY 4.0).

http://creativecommons.org/licenses/by/4.0/ (c) (i) Open Access

\begin{abstract}
E-commerce live broadcast is a kind of video live in the e-commerce platform. As an innovation of entrepreneurial marketing in the new media era, it quickly becomes the most important marketing method for many e-commerce sellers. Based on the characteristics of web live broadcast, this paper studies the path model of relationship between live video and customers' purchase intention from the perspective of telepresence. Through the empirical analysis, it is found that the vividness, interactivity and authenticity of live video enhance consumers' purchasing intention by affecting consumers' sense of immediacy and trust. Research results affirm the rationality for e-commerce sellers to introduce live broadcast marketing. Studies of detailed influencing paths allow sellers to evaluate marketing activities from the perspective of customers' mentality, to better understand the effect of live broadcast and finally to optimize marketing strategies.
\end{abstract}

\section{Keywords}

Broadcast Characteristics, Telepresence, Trust, Purchasing Intention

\section{Introduction}

With the rapid development of Internet technology and the popularity of intelligent terminals, interpersonal interaction is increasingly frequent. Against the background, web live broadcast has gained favor from the vast number of users since it was born due to its vividness, interaction and realness. Live broadcast bridges sellers' needs and customers' purchasing demand, thus complementing supply and demand. The highly visualized and interactive video broadcast allows customers to see others' fitting process and their feelings. In addition, a user may communicate with host and other users through bullet screen. This interactive mode solves the credibility dilemma in the e-commerce and boosts customers' decision-making confidence. In this paper, the author firstly investigates the 
path model of web live broadcast's effect on customers' purchasing intention from the perspective of sense of immediacy. Afterwards, the questionnaire data verify the path model. Lastly, efforts are focused on exploring possible webcast marketing methods that enterprises could take.

\section{Literature Review and Hypothesis}

\subsection{Related Definitions}

Purchase intention is the possibility that a consumer buys a product or service after gaining some understanding about it. According to Fishbei's behavioral intention model, the purchase behavior is the result of the purchase intention. Therefore, researches about purchase intention among online consumers are of great significance to $\mathrm{B} 2 \mathrm{C}, \mathrm{C} 2 \mathrm{C}$ and other e-commerce merchants.

In the academic circle, there is no unified definition about webcast. However, webcast is widely seen as a kind of interactive broadcast in the Internet. Mobile Internet is its base. Mobile terminals such as cellphone and broadcast applications are technical support. It's a real-time presentation and interactive broadcast model with interest as starting point. This paper adopts the widely-accepted view that e-commerce webcast is a new kind of marketing method that features broadcast in online e-commerce platform. Currently, there are many studies about e-commerce. However, domestically, studies about webcast, a new kind of media that gradually comes into the sight of customers with the development of Internet and terminal technologies, are scarce. The web live broadcast combines text, images, sound and other various expression elements, making broadcast more intuitive and vivid, and bringing realness, interactivity and vividness characteristics. Could it play a more direct stimulating role in customers' purchasing decision-making process than dull commodity presentation on the website? The paper aims to study the problem and to further explore detailed function path.

The concept of sense of immediacy was originated from "long-distance telepresence". It was initially widely used in communication. The sense of immediacy is made up of two parts: the space telepresence and the social telepresence. The division method was first proposed by the scholar IJsselsteijn. The so-called space telepresence means an immersive feeling that users experience with the aid of a certain kind of medium. The so-called social telepresence means the user shares the same presence feelings as others.

Features such as virtuality, the separation of time and space add risks and uncertainties to online shopping in the Internet, further reducing trust, a kind of emotional bond between sellers and buyers. Existing studies of online purchasing intention reveal that trust between people and products, including customers' confidence in website, sellers, products and reputation may significantly affect purchasing intention. Different from traditional shopping environment, online shoppers can't touch products before they buy them, thus they face higher risks in their purchasing behavior. Studies show that sense of immediacy is an important element for customers to increase trust and viscosity in website. 
Hence, in this paper, based on research results of predecessors, efforts are focused on studying the role and effect of video broadcast on the purchase intention of consumers during their online shopping.

\subsection{The Effect of the Video Live Feature on the Sense of Immediacy and Trust}

"Interactivity" is the dominant feature of webcast. Through webcast, customers can vividly feel host's temperance, mental aura and body languages. The bullet screen allows customers to directly interact with others. The real-time interaction creates the atmosphere that all customers are present at the scene, giving them strong sense of immediacy.

Many scholars have studied the relationship between online interaction and sense of immediacy. For example, when Hoffman investigated people's communication and interaction in the internet, he found that there existed a positive correlation between interaction and sense of immediacy. When He Miao conducted studies about online teaching, he found interaction between teachers and students or among students enhances social telepresence.

In addition, many scholars conducted many in-depth researches about their relationship in online shopping environment. For instance, Hassanein found that social telepresence can be strengthened due to text and photo design in the website [1]. Mollen's research revealed that customers are stimulated by the online e-commerce website. The stimulation is throughout the following three links of interaction, sense of immediacy and devotion [2]. Research findings of Skadberg et al. confirmed that interaction level was positively correlative to customers' virtual experience. The higher virtual experience was, the stronger sense of immediacyit brought to customers [3]. Videos were more intuitive and persuasive than other expression media such as pictures and words. Besides, the real-time interaction of video broadcast was more effective.

Lee found that the professionalism and richness of information as well as the life-like nature of website environment can boost customers' trust [4]. Tang Jiageng' study confirmed that interaction had a significant positive impact on trust. Zhao Hongxia et al. found communication between customers and e-commerce sellers can enhance consumers' trust in online shopping [5]. The assumptions are as follows:

$\mathrm{H} 1$ : The interactive feature of webcast has a positive impact on the generation of sense of immediacy

$\mathrm{H} 2$ : The interactive feature of webcast positively affects customers' trust

According to the division of sense of immediacy by IJsselsteijn, detailed hypothesis is put forward as follows:

H1a: The interaction feature of webcast exerts a positive influence on space telepresence

H1b: The interaction feature of webcast has a positive impact on social telepresence

Different from the traditional TV program, real-time webcast allows no edit- 
ing or other modification. It directly broadcasts what it is happening at the moment. From the perspective of information broadcast, pictures can be embellished, words can be fabricated, video can be edited. However, live video empowers watchers to have a real-time connection with the live scene and gain the most direct, real engagement experience. In addition, real-time broadcast reduces information loss during the process of multi-level transmission, thus guaranteeing the most authentic information. The realness of real-time broadcast enhances customers' engagement and trust. Ferris, Smith et al argue that the authentic perception of media content can predict individuals' recognition of the views and attitudes conveyed in the content [6]. Accordingly, the following assumptions are proposed:

H3: The realness feature of video broadcast positively influences telepresence

H3a: The realness feature of video broadcast positively influences space telepresence

H3b: The realness feature of video broadcast positively influences social telepresence

H4: The realness feature of video broadcast positively influences customers' trust

Vividness means the rich and diverse media environments, as well as various ways in which media convey information to sense organs. Web live broadcast uses many communication symbols such as texts, images, sound to convey information. It can better immerse customers to specific scenes or atmosphere compared than dull static websites. It stimulates customers' purchasing intention through the sense of immersion throughout all links. In terms of expression methods, it shares a lot of similarities with web advertisement. Beytt's research stated that the diversified expressions of web advertisement convey more information to browsers, leaving them a deep impression and stimulating their purchasing intention. According to researches of Steuer and Coyle, the vividness of web advertisement, either of its content or expression methods can bring deep and enjoyable experience for users [7] [8]. Thus, the hypothesis is as follows:

H5: The vividness of video broadcast positively affects customers' telepresence

H5a: The vividness of video broadcast positively affects customers' space telepresence

H5b: The vividness of video broadcast positively affects customers' social telepresence

H6: The vividness of video broadcast positively affects customers' trust

\subsection{The Effect of the Sense of Immediacy on the Trust}

Waller et al. argue that social telepresence is the necessary condition for the generation of trust in the virtual Interwork environment since trust is usually generated in the social environment [9]. Therefore, the rich sense of immediacy brought by online shopping environment enhances trust among customers; Gefen's research based on e-commerce service scenario reveals that social telepre- 
sence affects the generation of trust in customers [10]; Song proposed that in apparel selling websites, the sense of immediacy exerts a positive influence in the generation of trust among customers [11]; Nichaya's result finding points out that customers' trust is not only affected by social telepresence but also by space telepresence. In addition, the sense of immediacy affects customers' purchasing behavior through the media of trust. Skadberg et al. regard the sense of immediacy as one feature of "immersive experience" [3]. Many scholars verified that immersive experience can stimulate customers' trust. Based on it, hypothesis was as follows:

H7: Sense of immediacy positively affects customers' trust

H7a: Space telepresence exerts a positive influence in customers' trust

H7b: Social telepresence positively affects customers' trust.

\subsection{The Effect of the Sense of Immediacy and Trustoncustomers' Purchasing Intention}

$\mathrm{Li}$ argues that in three dimensional (3D) online shopping environment, customers give a high evaluation of products due to strong sense of immediacy and are more likely to purchase products; The result is confirmed by Kisoo. In previous studies, trust was chosen as an intermediate by scholars to study its role in the decision-making process when customers purchase a product. Zeithaml, Berry \& Parasurama believe that when customers feel trustful of a product or an enterprise, he would generate purchasing intention; Hong et al. argue that customers' trust in a brand would ultimately translate into loyalty and purchasing intention of the brand. Based on it, the hypothesis is raised as follows:

H8: sense of immediacy positively affect customers' purchasing intention

H8a: space telepresence positively affects customers' purchasing intention

H8b: social telepresence positively affect customers' purchasing intention

Hypothesis H9: customers' trust in a brand positively affects their purchasing intention.

The model was constructed as Figure 1.

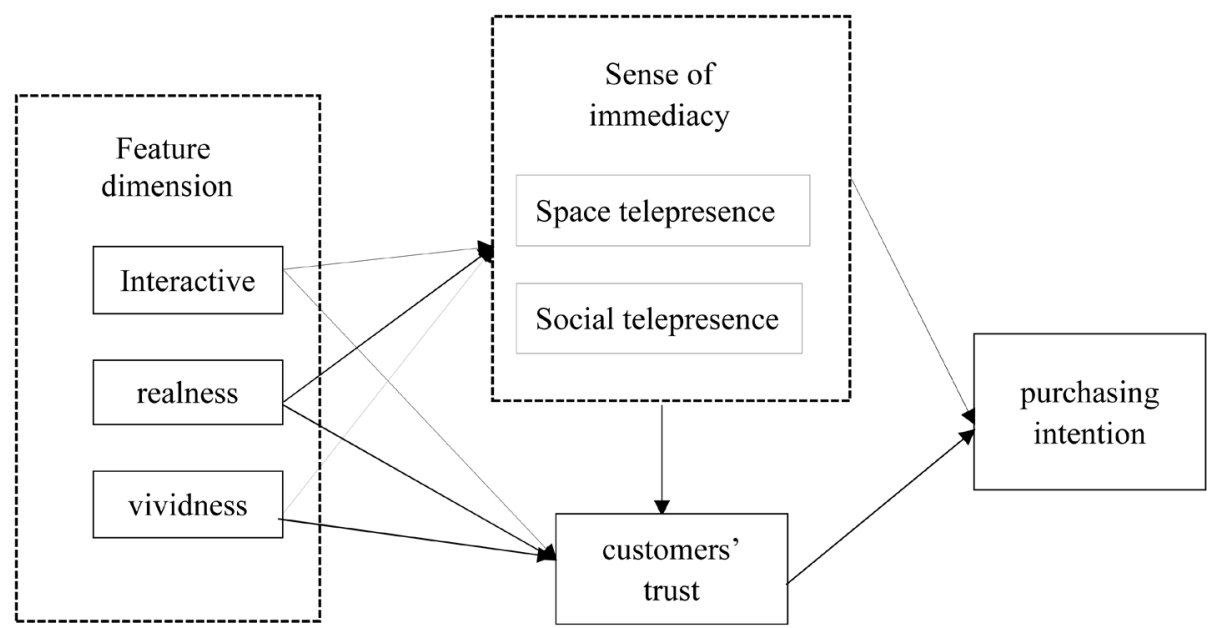

Figure 1. Research model. 


\section{Methodology}

\subsection{Questionnaire Structure and Variable Measurements}

In this paper, Likert's seven-part scale is employed to measure each dimension. Measurement of interaction mainly refers to Ridings and Wu's scales. The design of interaction measurement takes account of key factors in live broadcast, namely interaction between customers and the host, as well as interaction among customers; The measurement of realness mainly refers to realness perception scale of media content compiled by Rubin [12]; Measurement of vividness refers to the scale developed by Sheng H and Walters G [13]; Measurement of sense of immediacy draws on the scale designed by Barfield, Hassanein and Zhao Hongxia; Measurement of trust refers to the research made by Kantsperger, Kunz, Hesseler and McKnight; Scale of purchasing intention mainly consults the Dodds and Andrea's survey about online purchase intention.

\subsection{The Sample and Data Collection}

The main research object of the questionnaire is the online shopping users, and in the course of the shopping have watched the video broadcast experience. Among questionnaire respondents, only those who have watched live video broadcast when they shop on e-commerce platforms have access to the remaining part of the questionnaire. For those who answer they haven't watched, they would directly jump to characteristic statistic. Statistics are collected from online questionnaire. A total of 367 questionnaires are collected, among which 289 questionnaires are effective, with an effective rate of $79 \%$. The proportion of male respondents to female respondents are $52.3 \%$ to $47.7 \%$. The age group is mainly distributed in the interval of 16 - 40 years old. The sample structure roughly correspondents to the features of online shoppers.

\subsection{Methods of Data Analysis}

SPSS was used to analyze the reliability and validity of the data, Cronbach $\alpha$ coefficient is used to test the scale reliability. Cronbach $\alpha$ coefficient is a commonly used reliability analysis coefficient, which is between 0 and 1 , it is very suitable for analyzing the Likert scale. The larger the a coefficient, the higher the correlation coefficient between each item of the variable, and the higher the internal reliability. And then perform the validity analysis. Using AMOS statistical software to verify the fitting index of the model, If the CMIN/ DF, GFI, AGFI, IFI, CFI, RMSEA and other indicators meet the requirements, then the model is better.

\section{Results Analysis}

\subsection{Reliability and Validity Analysis}

The validity measurement examines the effectiveness and accuracy of the measurement result. First and foremost, according to sample measurement done by $\mathrm{KMO}$ and Bartlett, the value of KMO is greater than 0.8, which is 0.929 . The 
good validity and significance level of Barlett inspection $(\mathrm{P}<0.001)$ indicate that the questionnaire's structure is effective. In terms of factor analysis, factor loads are all greater than the standard of 0.7 , indicating convergent validity of variables are good. Detailed description is shown in Table 1.

\subsection{Structural Equation Model Analysis}

In this paper, structural equation hypothesis testing and the sample data statistical analysis using the software, AMOS17.0. In the model, each standardized factor loading volume is between 0.4 to 0.9 , and reached the significant level. Fit indices are as follows: $\chi^{2} / \mathrm{df}=4.783$, RMSEA $=0.047$ less than 0.05 ; AGFI $=$

Table 1. Reliability and validity analysis.

\begin{tabular}{|c|c|c|c|c|}
\hline Variable & Question & factor loading, (FL) & Cronbach'a & $\mathrm{KMO}$ \\
\hline \multirow{4}{*}{ Interactive IN } & IN1 & 0.877 & \multirow{4}{*}{0.884} & \multirow{4}{*}{0.875} \\
\hline & IN2 & 0.857 & & \\
\hline & IN3 & 0.849 & & \\
\hline & IN4 & 0.861 & & \\
\hline \multirow{4}{*}{$\begin{array}{c}\text { realness } \\
\mathrm{R}\end{array}$} & $\mathrm{R} 1$ & 0.920 & \multirow{4}{*}{0.954} & \multirow{4}{*}{0.876} \\
\hline & $\mathrm{R} 2$ & 0.897 & & \\
\hline & R3 & 0.888 & & \\
\hline & $\mathrm{R} 4$ & 0.862 & & \\
\hline \multirow{4}{*}{ vividness VI } & VI1 & 0.857 & \multirow{4}{*}{0.931} & \multirow{4}{*}{0.864} \\
\hline & VI2 & 0.852 & & \\
\hline & VI3 & 0.838 & & \\
\hline & VI4 & 0.793 & & \\
\hline \multirow{4}{*}{$\begin{array}{c}\text { Space } \\
\text { telepresencePh }\end{array}$} & $\mathrm{Ph} 1$ & 0.838 & \multirow{4}{*}{0.885} & \multirow{4}{*}{0.829} \\
\hline & $\mathrm{Ph} 2$ & 0.896 & & \\
\hline & $\mathrm{Ph} 3$ & 0.879 & & \\
\hline & $\mathrm{Ph} 4$ & 0.865 & & \\
\hline \multirow{6}{*}{$\begin{array}{l}\text { Social } \\
\text { telepresenceSh }\end{array}$} & Sh1 & 0.799 & \multirow{6}{*}{0.931} & \multirow{6}{*}{0.922} \\
\hline & Sh2 & 0.896 & & \\
\hline & Sh3 & 0.891 & & \\
\hline & $\mathrm{Sh} 4$ & 0.844 & & \\
\hline & Sh5 & 0.870 & & \\
\hline & Sh6 & 0.898 & & \\
\hline \multirow{4}{*}{$\begin{array}{c}\text { customers' } \\
\text { trust } \\
\text { ONT }\end{array}$} & ONT1 & 0.892 & \multirow{4}{*}{0.953} & \multirow{4}{*}{0.875} \\
\hline & ONT2 & 0.886 & & \\
\hline & ONT3 & 0.873 & & \\
\hline & ONT4 & 0.864 & & \\
\hline \multirow{4}{*}{$\begin{array}{l}\text { purchasing } \\
\text { intention PI }\end{array}$} & PI1 & 0.888 & \multirow{4}{*}{0.920} & \multirow{4}{*}{0.846} \\
\hline & PI2 & 0.781 & & \\
\hline & PI3 & 0.785 & & \\
\hline & PI4 & 0.802 & & \\
\hline
\end{tabular}


$0.802, \mathrm{NFI}=0.906, \mathrm{CFI}=0.922$ greater than 0.8 , Fitting index values are in line with the requirements, which indicated that model fit of the theoretical model is well. According to the above hypothesis testing, Table 2 is as follows.

\subsection{Hypothesis Testing}

Table 3 shows the hypothesis testing and path coefficients. The testing result shows that in terms of hypothesis $\mathrm{H} 3$ that states the relationship between the realness of video broadcast and customers' telepresence, the result of sub-hypothesis $\mathrm{H} 3 \mathrm{a}$ is significant while that of $\mathrm{H} 3 \mathrm{~b}$ is insignificant. It indicates that the realness of e-commerce broadcast has positive influences in enhancing customers' space telepresence but has insignificant influences in social telepresence; While in terms of $\mathrm{H} 5$ that states the relationship between vividness of live broadcast and customers' sense of immediacy, the result of sub-hypothesis H5a is significant, but that of $\mathrm{H} 5 \mathrm{~b}$ is insignificant. It indicates that vividness of e-commerce broadcast has significant effect on enhancing customers' space telepresence but little effect on social telepresence; in addition, the insignificant

Table 2. Model fitting index.

\begin{tabular}{cccc}
\hline Model fitting index & reference standard & result & meet a criterion \\
\hline $\mathrm{X}^{2} / \mathrm{df}$ & $<5$ & 4.783 & Yes \\
NFI & $>0.9$ & 0.906 & Yes \\
IFI & $>0.9$ & 0.923 & Yes \\
CFI & $>0.9$ & 0.922 & Yes \\
AGFI & $>0.8$ & 0.802 & Yes \\
RMSEA & $<0.05$ & 0.047 & Yes \\
\hline
\end{tabular}

Table 3. Results summary of hypothesis testing.

\begin{tabular}{|c|c|c|c|c|}
\hline Hypothesis & Relationship among variables & Coefficient & $\mathrm{p}$ & $\begin{array}{l}\text { Testing } \\
\text { results }\end{array}$ \\
\hline $\mathrm{H} 1 \mathrm{a}$ & Interactive $\rightarrow$ Space telepresence & 0.319 & $* * *$ & Support \\
\hline $\mathrm{H} 1 \mathrm{~b}$ & Interactive $\rightarrow$ Social telepresence & 0.281 & $* * *$ & Support \\
\hline $\mathrm{H} 2$ & Interactive $\rightarrow$ customers' trust & 0.137 & 0.009 & Support \\
\hline $\mathrm{H} 3 \mathrm{a}$ & Realness $\rightarrow$ Space telepresence & 0.349 & $* * *$ & Support \\
\hline $\mathrm{H} 3 \mathrm{~b}$ & Realness $\rightarrow$ Social telepresence & 0.022 & 0.069 & Not Support \\
\hline $\mathrm{H} 4$ & Realness $\rightarrow$ customers' trust & 0.169 & $* * *$ & Support \\
\hline $\mathrm{H} 5 \mathrm{a}$ & Vividness $\rightarrow$ Space telepresence & 0.184 & 0.011 & Support \\
\hline $\mathrm{H} 5 \mathrm{~b}$ & Vividness $\rightarrow$ Social telepresence & 0.036 & 0.074 & Not Support \\
\hline H6 & Vividness $\rightarrow$ customers' trust & 0.026 & 0.638 & Not Support \\
\hline $\mathrm{H} 7 \mathrm{a}$ & Space telepresence $\rightarrow$ customers' trust & 0.347 & 0.002 & Support \\
\hline $\mathrm{H} 7 \mathrm{~b}$ & Social telepresence $\rightarrow$ customers' trust & 0.593 & $* * *$ & Support \\
\hline $\mathrm{H} 8 \mathrm{a}$ & Space telepresence $\rightarrow$ purchasing intention & 0.281 & $* * *$ & Support \\
\hline $\mathrm{H} 8 \mathrm{~b}$ & Social telepresence $\rightarrow$ purchasing intention & 0.232 & $* * *$ & Support \\
\hline H9 & customers' trust $\rightarrow$ purchasing intention & 0.544 & $* * *$ & Support \\
\hline
\end{tabular}


result of Hypothesis H6 shows that vividness exerts insignificant influences in boosting customers' trust; Other hypothesis results are all significant.

\section{Discussions}

\subsection{Enlightenments}

As a popular mode of transmission, web live broadcast has attracted attention from many enterprises and investors, as well as favor of online sellers since it was born. Like previous network communities, it becomes an important platform for sellers to promote products and cultivate fans. In this paper, efforts are focused on discussing the relationship between e-commerce broadcast and customers' purchasing intention, on putting forward detailed effectiveness paths and providing new perspectives and trains of thoughts.

This paper verifies that vividness, interaction and realness of e-commerce broadcast have positive influences in customers' purchasing intention, affirming the rationality for online sellers to introduce the broadcast marketing method.

Unlike traditional entertainment broadcast, e-commerce broadcast is a new and complementary platform. It is a new breakthrough for e-commerce. The research in this paper is conducive for sellers to make evaluation of marketing activities through customers' psychologies, to better understand the broadcast's real effect, and to optimize marketing strategies.

In addition, the effect of e-commerce broadcast affects customers' purchasing intention by enhancing customers' sense of immediacy and trust of online shopping. The influencing path further indicates the importance of sense of immediacy and trust in customers' decision-making process in the virtual Internet environment. It offers reference for sellers to adopt other marketing strategies.

\subsection{Limitations and Future Work}

In this paper, the research object is the increasingly overwhelming network ecommerce. Efforts are focused on investigating the influence of newly emerged webcast in customers' purchasing intention. Apart from inherent features of webcast as a new media, other features or elements of webcast affect customers' purchasing decision-making process. In addition, enterprises allow customers to have a deeper understanding of itself and its brand through webcast marketing. Therefore, research areas of future study could be further expanded, and efforts could be focused on studying other elements in webcast.

\section{References}

[1] Hassanein, K. and Milena, H. (2007) Manipulating Perceived Social Presence Through The Web Interface and Its Impact on Attitude Towards Online Shopping. International Journal of Human-Computer Studies, 65, 689-708.

[2] Mollen, A. and Wilson, H. (2010) Engagement, Telepresence and Interactivity in Online Consumer Experience: Reconciling Scholastic and Managerial Perspectives. Journal of Business Research, 63, 919-925.

[3] Skadberg, Y.X. and Kimmel, J.R. (2004) Visitor's Flow Experience While Browsing a 
Web Site: Its Measurement, Contributing Factors and Consequences. Computers in Human Behavior, 20, 403-422.

[4] Lee, E. (2002) Factors That Enhance Consumer Trust in Human-Computer Interface Interaction: An Examination of Interface Factors and The Moderating Influences. The University of Tennessee Knoxville.

[5] Zhao, H.X., Wang, X.H. Zhou, B.G., et al. (2015) Research on Online Interaction and Telepathy and Consumer Trust in B2C Online Shopping. Journal of Management Review, 27, 43-54.

[6] Ferris, A.L., Smith, S.W., Greenberg, B.S. and Smith, S.L. (2007) The Content of Reality Dating Shows and Viewer Perceptions of Dating. Journal of Communication, 57, 490-510. https://doi.org/10.1111/j.1460-2466.2007.00354.x

[7] Steuter, J. (1992) Defining Virtual Reality: Dimensions Determining Telepresenee, Journal of Communication, 42, 73-93.

[8] Coyle, J.R. and Thorson, E. (2001) The Effects of Progressive Levels of Interactivity and Vividness in Marketing Sites. Journal of Advertising, 30, 65-77.

[9] Walters, G., Sparks, B. and Herington, C. (2007) The Effectiveness of Print Advertising Stimuli in Evoking Elaborate Consumption Visions for Potential Travelers. Journal of Travel Research, 46, 24-34. https://doi.org/10.1177/0047287507302376

[10] Gefen, D. and Straub, D.W. (2004) Consumer Trust in B2C E-Commerce and The Importance of Social Presence: Experiments in E-Products and E-Services. The International Journal of Management Science, 32, 407-424.

[11] Song K., Marie, A.F. and Park J. (2007) Telepresence and Fantasy in Online Apparel Shopping Experience. Journal of Fashion Marketing and Management, 11, 553-570. https://doi.org/10.1108/13612020710824607

[12] Rubin, A.M. (1981) An Examination of Television Viewing Motivations. Communication Research-An International Quarterly, 8, 141-165.

[13] Sheng, H. and Joginapelly, T. (2012) Effects of Web Atmospheric Cues on Users' Emotional Responses in E-Commerce. AIS Transactions on Human-Computer Interaction, 24, 1-24.

Submit or recommend next manuscript to SCIRP and we will provide best service for you:

Accepting pre-submission inquiries through Email, Facebook, LinkedIn, Twitter, etc. A wide selection of journals (inclusive of 9 subjects, more than 200 journals)

Providing 24-hour high-quality service

User-friendly online submission system

Fair and swift peer-review system

Efficient typesetting and proofreading procedure

Display of the result of downloads and visits, as well as the number of cited articles

Maximum dissemination of your research work

Submit your manuscript at: http://papersubmission.scirp.org/

Or contact ojbm@scirp.org 